A science faculty member at a major research university discusses strategic approaches to mentoring undergraduate students within a holistic framework of personal and professional development. This chapter describes the concept of a coordinated mentoring effort across years and disciplines.

\title{
Full Human Presence: A Guidepost to Mentoring Undergraduate Science Students
}

\author{
Brian P. Coppola
}

Hovering over the detailed recommendations for successful mentoring relationships are a few big ideas. Above other things, faculty mentors are obliged to help students uncover their dreams and realize their potentials. Students come to us with their futures wide open with possibilities. Since mentoring cannot be separated from its academic context, work with students in higher education must address explicitly the variety of cultures that intersect at our institutions. Compared with universities of the past, the new multicultural multiversity contributes significantly to these cultural intersections. The simple problem of scale is another contributing factor. Many institutions are sprawling places where disciplinary differentiation, hence dis-integration, dominates the physical and intellectual structures. Reintegration to address dis-integration is a worthy goal (Coppola and Daniels, 1998). The seeds of reintegration are found in the growing tendency toward multi- and interdisciplinary work that can reunify the multiversity and have a direct impact on institutional as well as individual faculty and student identities. The role we assume as mentors is one of these identities.

The life of an academic scientist today means taking on roles that were either less demanding or nonexistent in times past. Time to sit and reflect, to carefully guide the education of students at a natural pace-these classic academic responsibilities can conflict with newer demands: seeking competitive funding, pursuing research agendas driven by predicting the "hot" area of investigation, and accumulating students, papers, and citations as a measure of scholarship. Carl Djerassi has characterized the "tribal culture 
of research scientists" as an "overwhelming desire for name recognition ... brutal competition ... Nobel Prize lust ..." (Djerassi, 1997). (A pointed rebuttal to Djerassi appeared soon after [Frank, 1997].) Life for students is different, too. Scott Russell Sanders (1999) appeals to faculty to combat what he calls the culture of despair. Sanders addresses the culture of undergraduate education, where the seeds of Djerassi's competitive consumer mentality may be sown early. There is little time to acknowledge moral values in intellectual pursuit. Even the idea that we in higher education could be serving some larger good, as Sanders concludes, seems a quaint 1960s anachronism. Small wonder that national programs and professional organizations have been spending time and effort on topics such as revitalizing undergraduate education, mentoring, and examining the nature of graduate education itself.

A rich literature on mentoring exists (for example, Noe, 1988; Schaverien and Cosgrove, 1997; Krockover, 1991; Tallitsch, 1996; and Broome, 1996), including programs and recommendations for the particular needs of women (Hartman, 1995) and members of underrepresented ethnic groups (Juarez, 1991). By far, one of the most comprehensive publications on mentoring is Adviser, Teacher, Role Model, and Friend (National Academy of Sciences, 1997). It is a guide to assist mentors and advisers in understanding how they might help students identify and respond to the challenges of becoming scientists or engineers. It summarizes features that are common to successful mentoring relationships. The chapters define mentoring, explain the different roles the mentor plays with students (faculty adviser, career adviser, skills consultant, and role model), makes recommendations for improving the quality of mentoring, and provides resources.

The mentor-mentee relationship in scientific research is honored and time-tested, though learning to conduct research when our colleges and universities were first established differed greatly from the formal system of scholarly development we know today. The idea of a professional identity based on one's training is still valid today. Chemical genealogy is a real way that chemists record their historical connection via a lineage of Ph.D. mentors (Rocke and Ihde, 1979; McCarty, 1969; Bartow, 1939; Graham, 1948). In writing about the profound influences upon us of spending four years in a chemistry research group, a colleague and I eventually recognized that we also attribute a number of our teaching behaviors to lessons we learned from our graduate adviser (Coppola and Pearson, 1998). Somewhat ironically, and also significantly, our adviser had rarely been an instructor for an undergraduate course. The lessons have been extrapolated from his example as a mentor who valued the purpose of graduate "school" as an educational environment for the scholarly development of graduate students rather than primarily as a vehicle to advance his career. Instructional lessons emerged from the consistency of our educational experiences. We learned by example. This is a fundamental piece of understanding about mentoring: decisions 
we make and actions we take are all lessons we provide in our roles as advisers, teachers, role models, and friends.

\section{A General Framework for Guiding Undergraduate Student Development}

In 1994, Stephanie J. Bird identified three overlooked aspects of professional development in science students: mentoring, ethics, and professional responsibility (Bird, 1994). These three aspects cut across the traditional dimensions of faculty scholarship, namely research, teaching, and service. Undergraduate students relate to faculty in three discrete roles: students as members of a research community, students as members (even temporarily) of a professional scientific program, and students as participants in higher education. The diversity of instructional needs and objectives creates a familiar tension in formal education between training students in the technical content of the disciplines and the more overarching liberal arts values. Such values describe some general intellectual objectives for education. Professional intellectual objectives are the overarching values for a more specific literacy at the disciplinary level (for example, "chemistry," "biology," or "science"). Instructors need to attend explicitly to the connection between the professional and general intellectual objectives, namely, to answer how learning science is connected to a liberal education. Last, individual courses are embedded within the richness of professional technical objectives, that is, the factual subject matter that typically is comprised in a written syllabus or table of contents. Technological progress in the disciplines and the detailed articulation of the professional technical subject matter should be exploited in order to make clear connections about how learning triple integrals or translating Goethe is not only representative of professional intellectual objectives, but also addresses general intellectual ones. The implied $3 \times 3 \times 3$ grid defines an interesting space in which to examine educational recommendations:

Triad 1: mentoring/ethics/(professional responsibility)

Triad 2: research/teaching/service

Triad 3: (general intellectual goals)/(professional intellectual goals)/(professional technical goals)

Many recommendations have been nicely summarized in the references, and these will not be recapitulated here (see Bird, 1994; Broome, 1996; Juarez, 1991; Krockover, 1991; National Academy of Sciences, 1997; and Noe, 1988). Instead, this chapter will reflect the author's work within the general framework implied above.

Beginning in 1989, the University of Michigan Department of Chemistry instituted a comprehensive change to its undergraduate curriculum. Details about the start of this program can be found elsewhere (Ege, Coppola, 
and Lawton, 1997; Coppola, Ege, and Lawton, 1997; Coppola and Daniels, 1996b). The strategies that have been used to create a culture of sustained reform that continues to this day are intertwined with practice, but they can be summarized. In particular, our strategies are (1) to treat good teaching as transcendent because when it is done well it seeks inclusiveness for all groups; (2) to explicitly identify and articulate goals as a kind of "informed consent" for students; (3) to link these goals with actual practices, which generally requires challenging behavioral changes: the intellectual "skill" must be accompanied by the affective "will" (Paris, Lipson, and Wixson, 1983; McKeachie, 1994); (4) to recognize that, like it or not, instruction transmits values that go beyond simple lessons about the subject matter; (5) to offer multiple entry points for different learning styles, and to encourage and support all students to move beyond their learning comfort zones; (6) to make the implicit explicit; (7) to encourage livinglearning communities that help students integrate their academic and social development in college; and (8) to promote group work as productive along many dimensions, and provide collaborative activities that allow for individual accountability within a cooperative framework.

Many of these strategies overlap with recommendations for genderequitable and multicultural mentoring. Women and other marginalized communities, who perhaps fall away or simply turn away faster than others, report a consistent and "depressing discouragement" (Manis, Thomas, Sloat, and Davis, 1989) with the nature of their science experiences, including the implied messages they receive from the faculty (Seymour and Hewitt, 1997). To paraphrase Seyhan N. Ege, a colleague at the University of Michigan: "What's bad for the canary is bad for the miner." In other words, what constitutes a bad interaction for only a few is also likely to be bad for a much higher fraction. These warnings should not be underestimated or ignored.

A recent public service announcement on mentoring suggested that to be a mentor you do not have to have all of the answers, you just have to be yourself. Taken together, the strategies and ideas suggested above and in the references converge on understanding and using rational human values when you are responsible for guiding the development of another individual. The NAS monograph (National Academy of Sciences, 1997) suggests three main areas of responsibility for mentoring. Mentors build respect (take others seriously, do not dictate, are frank and direct, guide with options, encourage all opinions, take fears seriously). Mentors encourage risk and independence while providing support (recognize that ability is not the same as aptitude, and must also be flavored by ambition; strike a balance between being flexible, permissive, and restrictive; put others first when it benefits their interests). Mentors build a trusting relationship (practice what you profess; reveal yourself and your decision-making; resist the temptations of power; listen to understand, looking beneath the surface of issues to understand motivation; encourage and reflect on feedback). 
Ultimately, mentoring is not an activity that can be turned on and off at will. Faculty members are mentors through all of their words and actions when they take on the public trust of education. Mentors directly influence how the next generation of mentors will behave. Another colleague on campus, Ralph Williams, uses the wonderful phrase "full human presence" to describe the combined professional and personal obligations of a faculty member to the responsibilities of guiding the development of students. "Full human presence" represents an ideal. It charges us to be honest and fully realized people in our interactions with those whom we mentor and educate. Ultimately, "full human presence" may be a particularly poignant idea in mentoring and educating undergraduate science students because the research literature indicates such a strong disidentification of young people from the scientists they see (Seymour and Hewitt, 1997; Seymour, 1992; Tobias, 1992).

\section{Listening to the Student Voice}

In preparation for writing this article, the following informal e-mail survey was distributed to the forty undergraduate chemistry and biochemistry research students being supported on summer fellowships at The University of Michigan. Eleven of these students were from other colleges and universities, and were participating in an NSF-sponsored Research Experiences for Undergraduates (REU) Site.

Please send me e-mail replies ... short or long, snippets or full sentences . . . on your experiences being a mentee in the following three circumstances. These may be positive or negative experiences (for some of you, they might even be about me!). You do not have to name names, and I will not reveal or connect your identity with any particular story.

1. Comment on your mentee experiences as an undergraduate research student. What has been done well or poorly as you have learned about life as a laboratory scientist? (Area label = Undergraduate Research)

2. Comment on your mentee experiences as an undergraduate science major. This could extend from particular events in your science courses to your interaction with faculty about science in general. (Area label = Science Major)

3. Comment on your mentee experiences as a college or university student. It is easy to overlook the fact that your development as a learner is also part of your higher education. Comment specifically about role models and their actions that you think have been influential on you. (Area label = University Student)

Seventeen students (43 percent, three of eleven from the REU program) replied. Individual items in each of the three areas were first categorized as being a positive or negative comment and then subcategorized according to 
the mentoring ideals from the prior section (related to showing respect, being supportive, or promoting a trusting relationship). Representative items in the Undergraduate Research area are provided here as an example.

Area: Undergraduate Research (positive; in other words, cited as a positive, supporting characteristic)

Showing respect: "I feel like part of the lab and not just a mentee"

Being supportive: "having to do the work myself, after nudging in the right direction"

Promoting trust: "telling personal stories about graduate school"

Area: Undergraduate Research (negative; in other words, cited as a deficiency)

Showing respect: "sometimes it was difficult to disagree with more experienced people"

Being supportive: "too little supervision: I am not always sure if I am doing the proper thing"

Promoting trust: "entering the research lifestyle was intimidating due to mentor's standards"

The numerical summary across all three categories is shown in Table 7.1.

Based on this snapshot, the three categories (respect, support, and trust) easily account for the 154 comments made by these seventeen students. By and large, these students have been in positive mentoring relationships (113, or 73 percent, of the comments describe positive interactions). Nearly all of the comments reflect the general principles found in the literature, such as "mentor takes time to talk about work, answer questions," "I learned about life," "being honest," "setting behavior by example: to work hard, and to love the work," "weekly meetings to report and brainstorm,"

Table 7.1. Summary of Survey Results

\begin{tabular}{llll}
\hline $\begin{array}{l}\text { Area } \\
\text { (number of replies) }\end{array}$ & $\begin{array}{l}\text { Respect } \\
\text { (pos/neg) }\end{array}$ & $\begin{array}{l}\text { Support } \\
\text { (pos/neg) }\end{array}$ & $\begin{array}{l}\text { Trust } \\
\text { (pos/neg) }\end{array}$ \\
\hline $\begin{array}{l}\text { Undergraduate } \\
\begin{array}{l}\text { Research } \\
(68 \text { replies) }\end{array}\end{array}$ & $\begin{array}{l}16 \mathrm{pos} / 3 \mathrm{neg} \\
(19 / 68=28 \%)\end{array}$ & $\begin{array}{l}18 \mathrm{pos} / 9 \mathrm{neg} \\
(40 \%)\end{array}$ & $\begin{array}{l}21 \mathrm{pos} / 1 \mathrm{neg} \\
(32 \%)\end{array}$ \\
$\begin{array}{l}\text { Science Major } \\
(61)\end{array}$ & $\begin{array}{l}11 \mathrm{pos} / 6 \mathrm{neg} \\
(28 \%)\end{array}$ & $\begin{array}{l}8 \mathrm{pos} / 7 \mathrm{neg} \\
(24 \%)\end{array}$ & $\begin{array}{l}18 \mathrm{pos} / 11 \mathrm{neg} \\
(48 \%)\end{array}$ \\
$\begin{array}{l}\text { University Student } \\
(25)\end{array}$ & $\begin{array}{l}1 \mathrm{pos} / 2 \mathrm{neg} \\
(12 \%)\end{array}$ & $\begin{array}{l}11 \mathrm{pos} / 1 \mathrm{neg} \\
(48 \%)\end{array}$ & $\begin{array}{l}9 \mathrm{pos} / 1 \mathrm{neg} \\
(40 \%)\end{array}$ \\
\hline
\end{tabular}


"free to explore ideas ... within limits," "realistic (neither filled me with idealistic dreams nor scared me)," "left me with determination," "telling personal stories about personal activities," "putting a human feel on the science topics," "more inclined to like advisers when they know my background and interests," "answers questions, does not talk down to me but treats me as an equal who just has more learning to do," "patient," and "I admire mentors for seemingly natural actions, rather than actions manipulated to leave positive impressions." The implied context for the negative comments are also aligned with the main topics: "sometimes being watched too closely and not getting a chance to learn through errors," "I have not felt like a mentee," "I have had professors who did not seem to care about undergraduates," "not interested in pursuing the relationship if faculty intimidate," "professors preoccupied with their status," "lab work made too routine by instructors who provided answers too quickly, even shortcuts," "the more you talk to your TA or instructor, the better the grade ... this outraged me, so I did things on my own," and "faculty interaction is good, but it needs to go beyond posting office hours and then scolding if students do not attend them."

The relatively even distribution of comments in the research and general science area may be an indication of how robust these categories are for describing mentoring. Not surprisingly, the students are not as reflective about their general university education as they are about the more specific programmatic areas; this is an indication of student life in the dis-integrated university. The range of reasons offered by this sample of students reflects the value of full human presence in the classroom. Recently, The University of Michigan has been developing low-enrollment general-education seminars for first- and second-year students, as well as capstone courses. The discourse on our campus about these plans is centered on providing more reflective courses in the "liberal arts tradition" for our students. The results from this small survey are congruent with this need.

\section{Program Examples That Support Mentoring}

In this section, some of the specific courses and programs implemented by the author are described as models for the reader. These activities draw explicitly from the mentoring framework outlined above. Again, a few new directions for teaching and learning will be suggested here in lieu of recapitulating published work.

Developing the Scholarship of Teaching and Learning: Chemical Sciences at the Interface of Education. Graduate and postgraduate concerns about mentoring in science have focused on the next generation of scientists in their capacity as researchers. This target needs to be broadened without sacrificing the benefits to research, which means becoming more efficient at what we do. For over a decade, the Carnegie Foundation for the 
Advancement of Teaching has advocated a broader understanding of scholarship and its relationship to faculty work. In Scholarship Reconsidered, Ernest Boyer (1990) reminds us that scholarship is a mode of thought and a way of practice that can be applied to all aspects of faculty work.

Inasmuch as Scholarship Reconsidered provides a broadened answer to the question, What is scholarship?, its follow-up, Scholarship Assessed, answers the next implicit question, What tools do we use to distinguish the more scholarly from the less scholarly? (Glassick, Huber, and Maeroff, 1997). In the strength of its persuasive argument, Scholarship Assessed also provokes a new question, and that is, How does scholarship arise? If research is not the exclusive domain of scholarship, then understanding how we develop our research scholarship becomes a model for how we develop scholarship in general. Scholarship arises through a deliberately constructed infrastructure of professional development in which mentoring relationships play a large role. Through formal and informal work, undergraduates are identified for their scholarly potential and, in the majority of institutions today, provided with opportunities for increasing autonomy and responsibility through independent study and research. These same principles apply to graduate students, with some variation in the balance between formal course requirements, tasks such as proposals and seminars, and research. Research has become the focus of scholarship, and scholarship's infrastructure has become synonymous with the development of research skills. This development continues through the postdoctoral level and provides a momentum for a faculty member's professional career.

What would it look like to broaden the infrastructure of professional development to include the broadened notion of scholarship? In my work, I have been creating the pieces of the infrastructure that are devoted to the scholarship of teaching, beginning at the undergraduate level and extending to the faculty level. CSIE: Chemical Sciences at the Interface of Education (http://www.umich.edu/ csie) is a project devoted to creating and documenting exemplars within the professional development infrastructure that supports the scholarship of teaching in chemistry. We are exploring undergraduate curriculum design that allows students to have a mentored experience in examining their potential for teaching. Junior and senior students can move into more independent work in design, implementation, and assessment. In the graduate program, first-year chemistry Ph.D. students can take their cognate courses in education science or educational psychology and then work with experienced faculty in designing, implementing, and assessing curriculum ideas in our department. As in the department's research program, graduate students will soon play a significant role in the teaching program. In their third and fourth years, these students participate in weeklong mentored teaching internships at nearby institutions that are quite unlike our own. The next stages of this work are under way, where I am working with different disciplines at my own campus and with chemists at other institutions. We have also modeled work with postdoctoral students. 
Eventually, a multidisciplinary, multicampus network of institutions is needed so students can actually move through a system.

The CSIE argument underlies some recent recommendations for improving precollege education. At the end of "Some Features of a Flawed Educational System," an article in Daedalus, Seymour Sarason (1998) points out that blaming teachers for the inadequacies of education is blaming "the well-meaning victims of an educational system that they did not design." Ken Wilson and Constance Barsky, in the same issue, propose that only by studying and understanding the success of continuous change in our existing "sociotechnological systems" will we be able to bring lasting reform to education (Wilson and Barsky, 1998). They conclude that education is the system most in need of learning from applied research and development. Until we provide mentoring for a broadened notion of scholarship, we will not break free from repeating cycles of reinventing reform in each generation. What we call curriculum reform is more often than not faculty reeducation because the informed professional development of faculty for instruction is lacking. Larry Cuban asserts that the process of reform is itself unexamined (Cuban, 1990). In his essay, "Reforming Again, Again, and Again," Cuban concludes that "waves [of reform] occur on the surface [of formal education] and, in some instances, programs, like the skeletons of long-dead sea animals, get deposited on the coral reef of schooling ... [yet reform itself goes critically unexamined].... I end with a plea for rationality ... If we do not heed the plea, we will continue to mindlessly speculate, and as Gide observed, "Everything has been said before, but since nobody listens, we have to keep going back and begin again'" (p. 4).

Structured Study Groups. In our Structured Study Group (SSG) program, a cohort of 120 first-year students within the 1200-student Structure and Reactivity chemistry course (standard coursework and examinations) earns honors credit by participating in extra weekly two-hour sessions (Coppola and Daniels, 1996a). This supplemental instruction is shaped, metaphorically, along the lines of a performance studio in the arts. Assignments, in the form of common (not identical!) tasks, are subjected to peer presentation and peer critique facilitated by upper-level undergraduate leaders. Students in the structured study groups follow a detailed curriculum that helps them develop the kinds of skills that we believe are attached to a deep mastery of the subject matter in a format that encourages the students to also develop their more general learning skills, including their ability to work and communicate within the large, diverse setting of our institution.

During each session, the meeting time is typically divided between a number of activities. Each participant brings a duplicate set of his or her written assignments from the previous week. These assignments generally involve the creation of examples within a given context. In the first assignment, they pick a molecule from a chemistry journal (after learning, in their session, how to decode line formulas, what journals are, where they are found, and what a proper citation format is) and are directed to construct 
five rational examples of molecules with the same formula. They then propose rankings for their created molecules based on three of six chemical or physical properties. They must also include written descriptions of their rationales. Later, a typical assignment might be to find an example of a representative reaction in a chemistry journal and format it as a quiz problem appropriate to the level of the class. At the beginning of the session, each student submits one copy of his or her work to the peer group leader, and the other copy is distributed to the class. One or two rounds of peer review follow. The reviewer does not correct the other student's paper, but rather answers a set of factual questions about the other's work using an assessment sheet as guidance. During this time, the discussion within the group is freewheeling, and it is the time of greatest learning for the students. It also builds a strong sense of peer community, drawing from ideas such as respect, support, and trust, as these students share work with each other with the idea of productive critique. The first round of peer review can take up to an hour. Only when faced with reviewing the work of another can students deal with issues that were either incorrectly understood or that simply did not occur to them. After a second round of reviewing is completed, the reviews and the unmarked papers are returned to the originator and he or she has a chance to decide if any corrections are needed. This set of assignments and reviews are collected, and they form part of the basis for the leader's evaluation of the student's performance on that day.

Each term of the course in which structured study groups are used ends with a project that lasts a few weeks. In the first-term course, the students receive copies of two or three journal articles, usually short communications, in which chemistry appropriate to the experience of the students can be found. For three weeks, along with their last sets of assignments, the students create and edit a set of questions that might be asked of the author (usually one of our chemistry colleagues). During the last week of classes, the entire cohort of study group students meets with the author, who then fields the questions asked by the students. These sessions are quite powerful in their impact on the members of the class, who report wholesale shifts in their identities from "first-term chemistry students" to "members of a valid scientific discussion." Admittedly, we have taken a page from our colleagues in English, who, for example, routinely arrange meetings between students and the author of a piece that the class has been studying. The SSG curriculum covers a range of important topics. For example, we introduce formal ethical reasoning related to scientific practice (Coppola and Smith, 1996; Kovac, 1996; Kovac, 1999; Coppola, 2000). To end the second semester course, the students spend the last three weeks creating, refining, and peer editing their own case studies in scientific and professional ethics. Analyzing ethics cases is one of the tasks in the first term, too. In a separate section of the second-term course, students have a number of term-long projects, including generation of the text (in traditional print, HTML, and CD-ROM involving animations and other dynamic correlations) on which 
their final examination is based. More information about the SSGs can be found at http://www.umich.edu/ michchem/SSG (copies of the curricula for both terms and student-leader resources can be requested from the author).

The benefits of the SSG experience are not limited to its participants. Juniors and seniors, who are the group leaders, identify those participants who demonstrate potential for teaching excellence as the next generation of group leaders. This transition is the beginning of the professional development infrastructure described in the last section. From the beginning, SSG leaders have been collaborators on the design and delivery of the SSG program. Weekly sessions with the SSG leaders are informal, collaborative seminars on teaching and learning. The following quote is from one of my undergraduate teaching mentees, who had just completed his junior undergraduate year, in 1997. It is representative of a 1994-95 first-year student who demonstrated potential for teaching while participating in the SSG program, and someone who the CSIE program could more formally develop once he entered the junior year. He worked on independent teaching projects with me for three years, and on independent research with one of my colleagues. Before he left for graduate school, he and I had collaboratively designed, implemented, and assessed a curriculum project that in every way exceeds even the best independent study research project I have collaborated on with an undergraduate student. He writes, "The most important lesson I learned was that the 'teacher' is never just an instructor, but a student as well for the rest of their life. This became evident after going through the program first as a student and then as an instructor. ... I believe that my students taught me as much as I taught them, so I also had the opportunity to be a student myself. No matter how long a person has been involved with classroom instruction, I believe that they will always have things to learn if they allow it. A person never graduates from being a student, as there are always people that can teach them. This was an experience that I will never forget. It was an experience that made me realize my love for teaching chemistry. I hope that I will always be able to teach in a classroom, and I hope that I won't forget that I will always be a student."

\section{A Professional Development Capstone Course in the Chemical Sci-}

ences. At the end of the undergraduate curriculum, the department of chemistry has recently instituted a capstone course called Professional Development in the Chemical Sciences. The course is constructed around the variety of modes of expression that can characterize a life in science: written and oral, from short and long technical reports for various professional audiences to communicating with the public. The students in this course, nearly all of whom have participated in undergraduate research, once again revisit case studies in research ethics from the perspective of more experienced scientists. The majority of these students go on to graduate school or employment in chemical industry, so there is a strong practical component to this discussion. 
The "professional development" aspect of training chemical scientists includes but is not limited to research ethics. Over the past decade, perhaps partly as a result of the increasing number of cases of unprofessional and unethical practices, we recognize that unspoken and implicit instruction is clearly inadequate for the many practical and behavioral expectations of a life in science. As both academic and industrial scientists, we acknowledge the need to be more proactive in explicitly addressing the "rules of the game" of professional citizenship. Nationally, there is a groundswell of interest in how we introduce future scientists to the complex and challenging choices they must learn to make in their professional lives. Not only is the widely practiced "trial and error" method an unimaginably inefficient strategy, but the occurrence and consequences of professional malpractice are disturbingly high.

Some professional development issues occur naturally during the regular administration of courses, especially laboratory courses, and certainly in research, where issues in data and time management, "authorship," and responsible behavior are encountered daily. On the other hand, formal discussion can become too decontextualized or limited to putative response after a problem has already occurred. By creating a broad-based course, we provide an opportunity to reveal some of the complexities of a professional life in science in a way that will allow students a relatively safe and supervised environment. We have been influenced greatly by our industrial colleagues who report that their new employees, while adequately trained for the technical aspects of their work, have little professional experience where communication within a complex political and social structure is necessary. One of the 1999 research students who responded to the survey about mentoring is spending the summer interning at a nearby pharmaceutical research laboratory. As a student, he was a loner who actually disdained interaction with others because he wanted to prove something to himself about his independence. His advice to instructors after just a few weeks of his internship is telling: "I suggest that even though someone is keeping to himself or herself and does well, the instructor might want to intervene. I have learned through working in industry that it is really important to interact with those around you."

Student Organizations. The collective memory of the work of undergraduate student clubs is often fleeting, perhaps even more so than the memory of some academic faculty committees! Unlike fraternal organizations, with which members still identify long after they leave their student years, undergraduate students in preprofessional clubs more naturally disidentify with their organizations once they graduate and are no longer undergraduates. In addition, these clubs generally lack externally mandated local or national structures and so they end up tied strongly to their idiosyncratic institutional setting. As the faculty adviser for both the Alpha Chi Sigma chemistry fraternity and the American Chemical Society Student 
Affiliates (ACS-SA) at my institution, I have observed the relative consistency of the former group and the periodic peaks and troughs of the latter.

Like some of its earlier successful incarnations, the 1997-98 ("peak") group of ACS-SA at the University of Michigan owed a great deal to the individual students who came in on a "trough" and revived the program. Unlike with earlier incarnations, though, I have worked with these students to create some proactive strategies with which they hope to establish a structure and a tradition that will permit the organization to survive after the innovators have graduated. In this way, their problem is the same one we face in curriculum development: how to get innovations to survive the innovator so that we do not end up having to reform "again and again" (Cuban, 1990).

The work of these student affiliates contains lessons about allowing newcomers to take ownership, about cooperation and compromise, and about simple enthusiasm and love for the subject. Another strategy is contact and communication in a larger forum, so members of the group can more effectively learn from each other's experiences. Strategically, setting up a professional organizational structure has worked well. As an adviser, I am more of a collaborator with professional experience in the organization. My only requirement for the students is that they share ideas and strategies with me before enacting them. Similar to the case studies in research ethics that they study, I also ask them to examine explicitly the impact on stakeholders and the breadth of other issues related to their plans. I urge them to explore the things they can do within that limitation, and I support them in the independent efforts they undertake, including organizing over eight presentations and three peer-reviewed publications for which I am appropriately not a coauthor. Ironically, national American Chemical Society program officers have inserted my name on the author list for some of the presentations done by the ACS-SA. This example also illustrates that the main NAS areas (respect, support, and trust) work well to guide mentoring practices.

One-on-One Mentoring via the World Wide Web. By now, we are all accustomed to the benefits of electronic communication in bridging the distance between faculty members and undergraduate students. Those students who seek you out via electronic mail are not just the ones who visit you after class or at your office. The new medium opens new opportunities to a group from whom you might not have otherwise heard. Even when the invitation is open and repeated, what inspires a student to finally communicate with you? Using a personal Web site is another way to begin a mentoring opportunity.

\section{Faculty Responsibility and Moral Obligations}

Mentoring involves ideas and behaviors. When it comes to faculty behaviors, we have already made the point that the current mode of professional development falls short of its needs. Faculty members use their 
own graduate experiences and participate easily in meaningful conversations, and often-productive debates, about their research. Mentoring and teaching are an implicit part of the faculty contract. Yet conversations about these topics are limited and uninformed. Outside of schools of education, university faculty members are notorious for their disdain of pedagogy. We all know research scholars who seem to feel that knowledge of content is all that matters, and that attention to issues beyond this somehow dilutes or demeans the hard-earned value of subject-matter knowledge. If we provide a good course, full of the latest developments in our field, students will learn. We focus on teaching rather than learning, often with disastrous results. Lunch table conversations about current courses are often filled with destructive nostalgia about how much better students were "in the old days." Facilitating a broad-scale conversation about pedagogy is a difficult task, particularly in a university where faculty are engaged significantly in research, but a morally reflective educational practice (which is a type of content) demands that pedagogy be taken as seriously as factual content. At least in the public eye, students are the reason for the existence of the university. Their interests in a high-quality education that prepares them to be effective participants in the society are paramount. We must move beyond the views that (1) teaching is merely the organization and delivery of content, and (2) the primary goal of pedagogical innovation is the production of "artifacts" such as textbooks or, currently, interactive computer programs and Web sites. Pedagogical innovation requires changes in faculty behavior, the most difficult change of all. It is the difference between knowing (intellectually) that a good diet and regular program of exercise are truly the right things to do and observing that the world has plenty of overweight, sedentary physicians who also smoke. Behavioral changes are more complex and difficult than just changing one's mind. Because they require a change at the core, the process is slow. The first step is to facilitate a public discussion of pedagogy among university faculty, initially at the department level, eventually broadening so that ideas can be shared across disciplines. This is mentoring, too.

As heretical as it may sound, we can learn a great deal from the moral development of our medical school colleagues when it comes to how we "treat" our students: this above all else-first, do no harm. We have all observed first-hand (or perhaps simply heard from authoritative sources) too many examples of teaching and mentoring behaviors that we should never permit. These are uncomplicated issues of right and wrong. If we remain silent when we see or hear of these incidents then we are as guilty of abandoning our responsibilities as are the perpetrators. We fail as mentors. If we demonstrate our hypocrisy with "do as I say, not as I do" then we are as guilty as they. Mentors need to practice what they profess. We must have the moral courage to simply go to our intellectual offspring and say "no, what you are doing is wrong" instead of meeting behind closed doors and making whatever decision about these individuals fits our local custom. 
"First, do no harm" is not a prescript of inaction. It is a glaring reminder that our students have come to us for our care: for us to provide them with a rich environment in which they can improve themselves. If our students need our treatment, then we must diagnose carefully and wisely. On the day we earn our Ph.D. degrees, we faculty should be much better educated about the obligations of our profession. This is an obligation of mentoring. If we, by our words and actions, do not know how to provide the kinds of interventions that permit the majority of students to improve themselves, including every member of the next generation of faculty, then we may be guilty of negligence at best . . . and more often of actual harm. Ignorance is not an excuse. Full, open discourse about the scholarships of teaching and service and their inclusion in the professional development program for new faculty is the most morally defensible viewpoint for improving the state of teaching and learning.

\section{References}

Bartow, V. "Chemical Genealogy." Journal of Chemical Education, 1939, 16, 236.

Bird, S. J. "Overlooked Aspects in the Education of Science Professionals: Mentoring, Ethics, and Professional Responsibility." Journal of Science Education and Technology, 1994, 3, 49-55.

Boyer, E. L. Scholarship Reconsidered: Priorities of the Professoriate. Princeton, N.J.: Carnegie Foundation for the Advancement of Teaching, 1990.

Broome, T. "The Heroic Mentorship" Science Communication, 1996, 17, 398-429.

Coppola, B. P. "Targeting Entry Points for Ethics in Chemistry Teaching and Learning." Journal of Chemical Education 2000, 77, 1506-1511.

Coppola, B. P. and Daniels, D. S. "The Role of Written and Verbal Expression in Learning. Promoting and Improving Communication Skills for Students in an Undergraduate Chemistry Program." Language and Learning across the Disciplines, 1996a, 1(3), 67-86.

Coppola, B. P., and Daniels, D. S. "Structuring the Liberal (Arts) Education in Chemistry," Chemical Educator, 1996b, 1(2), S 1430-4171(96)02018-3. Available at http://journals.springer-ny.com/chedr.

Coppola, B. P., and Daniels, D. S. "Mea Culpa: Formal Education and the Dis-Integrated World" Science and Education, 1998, 7, 31-48.

Coppola, B. P., and Pearson, W. H. "Heretical Thoughts II. These on Lessons We Learned from our Graduate Advisor That Have Impacted on our Undergraduate Teaching." Journal of College Science Teaching, 1998, 27, 416-421.

Coppola, B. P., and Smith, D. H. "A Case for Ethics." Journal of Chemical Education, 1996, 73, 33-34.

Coppola, B. P., Ege, S. N., and Lawton, R. G. "The University of Michigan Undergraduate Chemistry Curriculum. 2. Instructional Strategies and Assessment," Journal of Chemical Education, 1997, 74, 84-94.

Cuban, L. "Reforming Again, Again, and Again." Educational Researcher, 1990, 19, 3-13.

Djerassi, C. Letter to the Editor. Chemical \& Engineering News, August 18, 1997, 8.

Ege, S. N., Coppola, B. P., and Lawton, R. G. "The University of Michigan Undergraduate Chemistry Curriculum. 1. Philosophy, Curriculum, and the Nature of Change," Journal of Chemical Education, 1997, 74, 74-83.

Frank, P. Letter to the Editor. Chemical E Engineering News, September 8, 1997, 6.

Glassick, C. E., Huber, M T., and Maeroff, G. I. Scholarship Assessed: Evaluation of the Professoriate. San Francisco: Jossey-Bass, 1997. 
Graham, R. P. "The Genealogy of a Chemistry Department." Journal of Chemical Education, 1948, 25, 632.

Hartman, I. S. "AIM: Attracting Women into Sciences." Journal of Chemical Education, 1995, 72, 711-713.

Juarez, C. E. "Recruiting Minority Students for Academic Careers: The Role of Graduate Student and Faculty Mentors." Political Science and Politics, 1991, 24, 539-540.

Kovac, J. "Scientific Ethics in Chemical Education." Journal of Chemical Education, 1996, 73, 926-928.

Kovac, J. "Professional Ethics in the College and University Science Curriculum" Science \& Education, 1999, 8, 309-319.

Krockover, G. R. "Reflections on Professorial Mentorships." Teaching Education, 1991, 3(2), 113-114.

Manis, J. D., Thomas, N. G., Sloat, B. F., and Davis, C.S.G. "Factors Affecting Choices of Majors in Science, Mathematics and Engineering at the University of Michigan." Center for the Education of Women Research Report. Ann Arbor, MI: Center for the Education of Women, 1989.

McCarty, C. N. "Chemical Genealogy." Journal of Chemical Education, 1969, 46, 317.

McKeachie, W. J. Teaching Tips (9th Ed.). Boston: Heath, 1994.

National Academy of Sciences. "Adviser, Teacher, Role Model, and Friend: On Being a Mentor to Students in Science and Engineering." Washington, D.C.: National Academy Press, 1997. Available at http://www.nap.edu/readingroom/books/mentor (viewed July 2, 1999).

Noe, R. A. "An Investigation of the Determinants of Successful Assigned Mentoring." Personnel Psychology, 1988, 41, 457-479.

Paris, S. G., Lipson, M. Y., and Wixson, K. "Becoming a Strategic Reader." Contemporary Educational Psychology, 1983, 8, 293-316.

Rocke, A. J., and Ihde, A. J. "A Badger Chemist Genealogy: The Faculty at the University of Wisconsin-Madison." Journal of Chemical Education, 1979, 56, 93.

Sanders, S. R. "Teaching Thoughtful Students the Rudiments of Hope," The Chronicle of Higher Education, Apr. 9, 1999, XLV(31), B4-B5.

Sarason, S. "Some Features of a Flawed Educational System," Daedalus, 1998, 127(4), 1-12.

Schaverien, L., and Cosgrove, M. "Learning to Teach Generatively: Mentor-Supported Professional Development and Research in Technology-and-Science." Journal of the Learning Sciences, 1997, 6, 317-346.

Seymour, E. "'The Problem Iceberg' in Science, Mathematics, and Engineering Education: Student Explanations for High Attrition Rates." Journal of College Science Teaching, 1992, 21, 230-232.

Seymour, E., and Hewitt, N. M. "Talking About Leaving: Why Undergraduates Leave the Sciences." Boulder, Colo.: Westview Press, 1997.

Tallitsch, R. B. "It's Time for a Change in the Way We Educate Physiology Ph.D. Candidates." Advances in Physiology Education, 1996, 16, S68-S70.

Tobias, S. "Women in Science-Women and Science." Journal of College Science Teaching, 1992, 21, 276-278.

Wilson, K., and Barsky, C. "Applied Research and Development: Support for Continuing Improvement in Education.” Daedalus, 1998, 127(4), 233-258.

BRIAN P. COPPOLA is an associate professor of chemistry at The University of Michigan, Ann Arbor. He is a faculty associate at The University of Michigan Center for Research on Learning and Teaching, and a Pew Scholar in the Carnegie Fellows program of the Carnegie Foundation for the Advancement of Teaching and Learning. He directs the Chemical Sciences at the Interface of Edu- 
cation program at The University of Michigan, which is devoted to creating and documenting exemplars within the professional development infrastructure needed to understand and promote the scholarship of teaching and learning. His area of instructional research interest is curriculum design, implementation and evaluation that are mediated by multidisciplinary collaboration between faculty in chemistry, education, and psychology. 
